\title{
Assessment of Community Pharmacy Professionals' Attitude and Perception Towards Ethical Issues in Amhara Region, Ethiopia: A Cross-Sectional Survey 2020
}

\author{
Wudneh Simegn (1D) \\ Berhanemeskel \\ Weldegerima $\mathbb{D}^{\prime}$ \\ Alem Endeshaw (D) \\ Gashaw Sisay ${ }^{2}$ \\ Abdulwase Mohammed (iD) ${ }^{2}$ \\ Dawit Wondimsigegn (1D' \\ Henok Dagne $\mathbb{D}^{3}$ \\ 'Department of Social and Administrative \\ Pharmacy, School of Pharmacy, University \\ of Gondar, Gondar, Amhara Region, \\ Ethiopia; ${ }^{2}$ Department of Clinical \\ Pharmacy, School of Pharmacy, University \\ of Gondar, Gondar, Amhara Region, \\ Ethiopia; ${ }^{3}$ Department of Environmental \\ and Occupational Health and Safety, \\ Institute of Public Health, University of \\ Gondar, Gondar, Amhara Region, \\ Ethiopia
}

Purpose: The objective of this study was to assess the attitude and perception of community pharmacy professionals' towards ethical issues.

Methods: We have undertaken a cross-sectional study among community pharmacy professionals in three selected towns (Gondar, Bahir Dar, and Debra Markos) of Amhara region in Ethiopia from February to March 2020. All community pharmacy professionals who were giving services during the data collection period were the study population. We used a pretested, semi-structured questionnaire developed from a review of previous study. Epiinfo 7.1 was used for data entry, and SPSS version 20 was used for data analysis. Logistic regression was done, and a variable with a p-value $<0.05$ with $95 \%$ confidence interval was considered to be associated with outcome variable.

Results: A total of 305 community pharmacy professionals participated in the study with a response rate of $95.3 \%$. About $252(82.6 \%)$ of respondents received education regarding professional ethics. Majority (89.8\%) of the participants had ever accessed ethical information at their work site. Only 145 (47.5\%) participants had ever recorded ethical issues in their working site. The most common reasons that obstruct to explain ethical issues to customers were shortage of time $(85.9 \%)$, unavailability of reliable resources $(40.0 \%)$, and poor ethical knowledge (37.7\%). The reporting rate of respondents is less than $50 \%$ for most ethical scenarios. Sex, age, educational status, work experience, number of customers per day, working site, information about ethics, and training about ethics were observed to have a significant association with attitude and perception of community pharmacy professionals towards ethical issues.

Conclusion: Community pharmacy professionals had poor attitude and perception towards ethical issues. Interventions should be devised to uphold ethical awareness of community pharmacy professionals. A large-scale study is also recommended.

Keywords: attitude and perception, community pharmacy professionals, ethical issues, ethical scenarios

\section{Introduction}

Community pharmacy professionals are the most accessible professionals with multifaceted pharmaceutical services. ${ }^{1-4}$ While disposing of their responsibility, they need to adhere to national regulations or standards of good pharmacy practice $^{3-5}$ and abide by professional ethics ${ }^{6,7}$ Pharmacy professional ethics is the values and ethical principles governing pharmacy practice that encourage the right 
professional conduct. It guides pharmacy professionals for tolerant care behind moral obligations and virtues. ${ }^{8,9}$

There is a significant change in pharmacy practice over the past 5 decades. ${ }^{10}$ Globally, the main focus of pharmacy professionals is shifting from product-oriented to patient-centered practice. Patient-centered practice requires the identification of the concerns and needs of patients and collaborating with other health professionals closely to ensure safe and effective utilization of medicines. ${ }^{11-13}$ This evolving practice together with ever-increasing complexity of cases, medications, and other contributing factors brings a rise of additional ethical dilemmas for pharmacy professionals. ${ }^{6,14-17}$ An "ethical dilemma" is operationalized as a "situation in which there is a choice between at least two courses of action, neither of which is morally correct". 18

Community pharmacy professionals in different countries are experiencing frequent and complex ethical dilemmas which compromise ethical pharmacy practice. ${ }^{6,8,15,19-21}$ They often run a commercial matter nearby their work sites which further augment the dilemmas. ${ }^{22,23}$ Community pharmacy practice results many ethical conflicts because of the advertisement flora and fauna of pharmacy, ${ }^{23}$ arising from conflicting personal, professional, institutional or societal values of the different parties involved. ${ }^{24-27}$ Moreover, the consumerist birds of community pharmacy and the co-modification of medicines have led to experiencing several conflicts. ${ }^{28}$

As far as Ethiopia is concerned, there are reports of malpractices in pharmaceutical services by community pharmacy professionals. ${ }^{29,30}$ However, there is no study that specifically assessed the overall ethical considerations of such professionals. Therefore, the purpose of the current study was to assess the attitude and perception of community pharmacy professionals towards ethical issues in selected towns of Amhara region. In Ethiopia, the term community pharmacy professional designates druggists or pharmacy technicians and pharmacists. Druggists or pharmacy technicians are diploma holders who completed a three years long pharmacy training. Pharmacists include those who had a bachelor degree and above certification, which according to the current nationally harmonized curriculum, is obtained after completion of a five years long pharmacy education for first degree and a follow-up post-graduate training.

\section{Methods}

\section{Study Setting, Design, and Period}

A cross-sectional survey was conducted among community pharmacy professionals in three towns of Amhara region (Gondar, Bahir Dar, and Debre Markos). Amhara regional state is located in the Northwest of Ethiopia. The region has 11 zones, 139 woredas (districts), and 3422 kebeles. It is the second-most populous region in the country. Bahir Dar is located approximately $565 \mathrm{~km}$ away from Addis Ababa, the capital city of Ethiopia. About 25 community pharmacies and 38 drug stores were found in Bahir Dar town. Gondar town is located about $738 \mathrm{~km}$ away from the capital. There were 20 community pharmacies and 35 drug stores in the town. Debre Markos is located $299 \mathrm{~km}$ away from Addis Ababa. There were 15 community pharmacies and 21 drug stores in the town. In Ethiopia, pharmacy and drug store differ in the range of medications allowed to stock or dispense and qualification of the professionals who run the retail outlets. Pharmacy is run by a licensed pharmacist with a minimum qualification of bachelor degree in pharmacy and drug store is run by licensed druggist or pharmacy technician with a minimum qualification of diploma in pharmacy. The community drug retail outlets give patientcentered services such as responding to symptoms, filling prescriptions, and patient counseling. The data was collected from February to March 2020.

\section{Population}

All community pharmacy professionals working in the three towns of the Amhara region and who were giving service during the data collection period were the study population.

\section{Inclusion and Exclusion Criteria}

All community pharmacy professionals who were present at the time of data collection were included. Those who had less than one year of work experience were excluded because, in the Ethiopian situation, they serve under close supervision of senior professionals and might not have a chance of getting ethical dilemmas on their own.

\section{Sampling}

No sampling was done as we used all three hundred and twenty actively serving pharmacy professionals in the three towns. The questionnaires were distributed to all community pharmacy professionals who were available at the working site during the study period.

\section{Data Collection Procedure}

A semi-structured, pretested self-administered questionnaire was used to collect the required data. The 
questionnaire was adopted from a previous study related to ethical issues in community pharmacy. ${ }^{22} \mathrm{~A}$ draft of the questionnaire was piloted on 15 pharmacy professionals out of the study area to check for understanding, questionnaire design, and the length of the questionnaire. After the pre-test, slight modifications were done on some components of the questionnaire to make it easily understandable by respondents.

The survey questionnaire consisted of closed-ended, multiple-choice, fill-in short answers, and statements (dilemmas). The questionnaire was constructed to include three sections. The first section included demographic information and close-ended questions about whether they received previous continuing education on ethics in pharmacy practice, or have accessed ethical information at the practice site. The second section included information about the frequency with which ethical issues are discussed with patients, whether they discuss ethical issues and how often the discussion was conducted in the pharmacy, the barriers that limit community pharmacy professionals from explaining ethical issues to their patients, available ethical information resources at practice sites, and perceived resources that would help care for patients. The third section included questions related with the frequency of occurrence of each possible ethical dilemma faced by the community pharmacy professionals. Nineteen different scenarios involving issues related to pharmacy professionals-patient and pharmacy professionals-colleague interaction which specifically cover scenarios including drug abuse, confidentiality and privacy, disruptive behaviors, self-prescription, dispensing without prescription and others were used in the survey (Table 1). Study participants were considered to have a positive attitude for specific scenario if they reported they have encountered a particular ethical dilemma irrespective of the frequency.

The data was collected by three trained pharmacists. A total of 320 questionnaires were distributed to all community pharmacy professionals during the study period. Non-respondents were telephoned and visited to return their questionnaire. Finally, we had collected the data from three hundred and five respondents (72 respondents in Gondar, 164 respondents in Bahir Dar, and 69 respondents in Debre Markos).

\section{Variables of the Study}

The dependent variable is attitude and perception towards ethical consideration. The independent variables are sex, age, marital status, work site, educational level, work experience, number of customers per day, ever received previous continuous education about ethics, ever accessed ethical information at the practice site, ever recorded ethical concerns, barriers that prevent from explaining ethical issues with customers, and availability of ethical references in drug retail outlets.

\section{Data Entry, Analysis and Interpretation}

We used Epi-info 7.1 for data entry. SPSS version 20 was used for further analysis. Mean with standard deviation, frequency of occurrence, and percentage were computed. Logistic regression was done to identify factors associated with the dependent variable. A bi-variable analysis was done to determine the crude association between the scenarios and each independent variable. Independent variables with a p-value $<0.2$ were selected for multivariable logistic regression. A variable with a p-value $<0.05$ with $95 \%$ confidence interval was considered to be associated with outcome variable.

\section{Data Quality Control}

Data quality was assured through the whole process starting from questionnaire design up to analysis and generating output. Pre-test was done before the actual data collection. Data collectors were rehearsed with the overview of the study and the process of data collection in such a way to come up with quality data.

\section{Results}

\section{Socio-Demographic Characteristics of Study Participants}

In this study, three hundred and five (305) respondents participated with a $95.3 \%$ response rate. The mean age of study participants was 27.8 years $( \pm 5.42)$ ranged from 20 to 65 years. One hundred and sixty-three (53.4\%) participants were males and one hundred and sixty-four (53.8) were married. Among the total of the study participants, above half of them were druggists or pharmacy technicians $(56.7 \%)$ and the majority of them were working in private pharmacies $(69.5 \%)$ (Table 2 ).

\section{General Information on Ethical Issues}

Two hundred and fifty-two (82.6\%) participants received previous continuous education on ethics. Majority of the participants $(89.8 \%)$ had ever accessed ethical information at the practice site. One hundred and forty-five (47.5\%) participants had ever recorded ethical issues in their working site. Significant of them (69.5\%) discussed ethical 
Table I Scenarios Used for Assessment of Ethical Issues Among Community Pharmacy Professionals in Amhara Region, Ethiopia, $2020(n=305)$

\begin{tabular}{|c|c|}
\hline $\begin{array}{l}\text { Scenario Number } \\
\text { Assigned }\end{array}$ & Scenarios \\
\hline I & $\begin{array}{l}\text { A customer asks for an over-the-counter treatment. After talking to the patient you conclude that s/he does not need } \\
\text { the treatment, though it would do no harm for him/her to use it }\end{array}$ \\
\hline 2 & $\begin{array}{l}\text { The prescription states a specific brand of drug. You do not have this in stock but you have a generic clinically } \\
\text { equivalent brand in stock }\end{array}$ \\
\hline 3 & A patient comes in for his/her controlled drug prescription but it is the day after the date specified on the prescription \\
\hline 4 & $\begin{array}{l}\text { After questioning, a patient makes it known s/he is going to use the medication she/he is asking to buy against guidelines } \\
\text { (eg hydrocortisone cream` for his/her face) }\end{array}$ \\
\hline 5 & $\begin{array}{l}\text { A customer wants to buy an over-the-counter medicine you suspect s/he might be abusing (maybe this appears likely } \\
\text { after speaking to him/ her about it) and the customer does not want an alternative }\end{array}$ \\
\hline 6 & $\begin{array}{l}\text { The husband or wife, or another close family member (other than the parent of a child) of a patient asks for } \\
\text { confidential information about that patient's treatment }\end{array}$ \\
\hline 7 & $\begin{array}{l}\text { Someone comes into the pharmacy/phones you asking you to identify a particular tablet that does not belong to him/ } \\
\text { her. You can identify the tablet }\end{array}$ \\
\hline 8 & $\begin{array}{l}\text { You believe that withholding the truth from, or deliberately misleading, a patient would mean s/he would be compliant } \\
\text { with a treatment you believe is very important to him/her }\end{array}$ \\
\hline 9 & A female comes in and asks for hormonal contraception. She says she is married, but you suspect she is not \\
\hline 10 & You feel something a colleague has done is unethical \\
\hline 11 & $\begin{array}{l}\text { You feel something a colleague has done is unethical and you talk to your colleague, but still s/he does not change his/ } \\
\text { her behavior }\end{array}$ \\
\hline 12 & A parent of a patient asks for confidential information about his/her son/daughter's treatment \\
\hline 13 & $\begin{array}{l}\text { A doctor is prescribing, on private scripts, medication you suspect s/he is abusing. You have already talked to him/her } \\
\text { about it but s/he has ignored you }\end{array}$ \\
\hline 14 & You Suspect a child, who is one of your patients, may be subject to abuse at home \\
\hline 15 & $\begin{array}{l}\text { You suspect a pharmacist you work with is using prescription medicine from the controlled drugs cabinet without } \\
\text { a prescription. You already talked to him/her about it but s/he clearly ignored you }\end{array}$ \\
\hline 16 & $\begin{array}{l}\text { A pediatric consultant has asked you to dispense, for a child, a dose of medicine that is outside the country national } \\
\text { formulary limits, but is still not at a toxic level. You speak with the consultant about it who confirms these are his/her } \\
\text { wishes }\end{array}$ \\
\hline 17 & $\begin{array}{l}\text { A consultant asks you to dispense a drug for an unreported indication and tells you s/he knows it is used for this } \\
\text { indication with great effect in the USA }\end{array}$ \\
\hline 18 & $\begin{array}{l}\text { A member of the public comes to the pharmacy and asks for some medication for someone else who is waiting at } \\
\text { home (eg his wife, who is in great distress). S/he tells you that the person for whom the medication is for has used the } \\
\text { medicine several times before and is very familiar with it for example digoxin }\end{array}$ \\
\hline 19 & $\begin{array}{l}\text { A terminally ill patient asks you for a diagnosis or prognosis, telling you s/he does not feel the doctor is telling the } \\
\text { whole truth. You know the full case history }\end{array}$ \\
\hline
\end{tabular}

issues when patients initiated the conversation. Most of the respondents reported that lack of time as the major barrier $(85.9 \%)$ that limits them from explaining ethical issues to their customers followed by lack of reliable resources $(40 \%)$ and gap in ethical knowledge (37.7\%). About $78.7 \%$ revealed that books were the primary ethical 
Table 2 Sociodemographic Characteristics of Study Participants, Amhara Region, Ethiopia, $2020(n=305)$

\begin{tabular}{|c|c|c|c|}
\hline Variable & Categories & Frequency & Percent \\
\hline \multirow[t]{2}{*}{ Sex } & Female & 142 & 46.6 \\
\hline & Male & 163 & 53.4 \\
\hline \multirow[t]{4}{*}{ Age in years } & $20-25$ & 204 & 66.9 \\
\hline & $26-35$ & 24 & 7.9 \\
\hline & $36-40$ & 40 & 13.1 \\
\hline & $40-65$ & 37 & 12.1 \\
\hline \multirow[t]{2}{*}{ Marital status } & Married & 164 & 53.8 \\
\hline & Unmarried & $14 \mid$ & 46.2 \\
\hline \multirow[t]{3}{*}{ Site of work } & Private drug store & 78 & 25.6 \\
\hline & Private pharmacy & 212 & 69.5 \\
\hline & Red cross community pharmacy & 15 & 6.9 \\
\hline \multirow[t]{3}{*}{ Education level } & Diploma (Pharmacy Technicians) & 173 & 56.7 \\
\hline & Bachelor degree (Pharmacist) & 113 & 37.0 \\
\hline & Masters and above (Pharmacist) & 19 & 6.2 \\
\hline \multirow{4}{*}{$\begin{array}{l}\text { Work } \\
\text { experience in } \\
\text { years }\end{array}$} & $\mathrm{I}-2$ & 27 & 8.9 \\
\hline & $2-5$ & 118 & 38.7 \\
\hline & $6-10$ & 110 & 36.1 \\
\hline & $>10$ & 50 & 16.1 \\
\hline \multirow{4}{*}{$\begin{array}{l}\text { Number of } \\
\text { customers } \\
\text { per day }\end{array}$} & $10-50$ & 82 & 26.9 \\
\hline & $51-70$ & 82 & 26.9 \\
\hline & $71-100$ & 75 & 24.6 \\
\hline & $>100$ & 66 & 21.6 \\
\hline
\end{tabular}

reference materials available in their pharmacy or drug store followed by internet (29.8\%) (Table 3).

\section{Response to Ethical Scenarios}

The reporting rate of respondents is less than $50 \%$ for most scenarios. The most frequent scenarios reported were confidentiality related to identifying a drug used by someone else (Scenario 7, 66.6\%), withholding truth and deliberately misleading a patient for compliance to treatment the pharmacist believed as important (Scenario 8, 57.7\%), dispensing generic clinically equivalent drug (Scenario 2, $56.7 \%$ ), disclosing confidential information for a parent (Scenario 12, 56.4\%) and dealing with an over-thecounter medication request which is not needed and result no harm (Scenario 1, 55.7\%). The least frequent scenarios encountered by the community pharmacy professionals were dispensing a prescription for an unreported indication (Scenario 17, 14.1\%), suspected child abuse (Scenario 14, $15.7 \%$ ), filling an overdose medication prescription against standard treatment guideline recommendation (Scenario $16,22.6 \%$ ) and a colleague suspected of taking controlled drug without prescription (Scenario 15, 25.6\%) (Table 4).

\section{Factors Associated with Response to} Scenarios

Sex, age, educational status, work experience, number of customers per day, working site, information about ethics and training about ethics were observed to have significant association with attitude and perceptions (scenarios) of community pharmacy professionals. Male sex $(\mathrm{AOR}=$ $0.44,95 \%$ CI (0.26-0.74)), having ten years and above work experience $(\mathrm{AOR}=2.41,95 \%$ CI $(1.42-4.08))$, diploma educational status $(\mathrm{AOR}=0.22,95 \% \mathrm{CI}(0.08-$ $0.63)$ ), training about ethics (AOR $=0.40,95 \%$ CI $(0.17-$ $0.91)$ ), and working in private pharmacy $(\mathrm{AOR}=0.20$, 95\% CI (0.06-0.62)) were significantly associated with confidentiality (Scenario 19). Having ten years and above work experience $(\mathrm{AOR}=0.27,95 \%$ CI $(0.14-0.50))$, number of customers (10-50 patients per day) $(\mathrm{AOR}=$ $5.18,95 \% \mathrm{CI}(2.30-11.71))$, working in private pharmacy $(\mathrm{AOR}=4.46,95 \% \mathrm{CI}(1.02-19.53))$, and having information about ethics (AOR $=0.23,95 \%$ CI $(0.08-0.68)$ ) were determinant factors for prescribing generic clinically equivalent drug (Scenario 2). Number of customers (1050 patients per day) $(\mathrm{AOR}=2.62,95 \% \mathrm{CI}(1.09-6.31))$, working in private drug store $(\mathrm{AOR}=0.09,95 \% \mathrm{CI}(0.03-$ $0.34)$ ), working in private pharmacy $(\mathrm{AOR}=0.23,95 \% \mathrm{CI}$ (0.08-0.70)), and having information about ethics (AOR = $0.30,95 \%$ CI $(0.13-0.64)$ ) were significantly associated with about dispensing controlled drugs (Scenario 3). Having ten years and above work experience $(\mathrm{AOR}=$ $2.87,95 \%$ CI (1.64-5.05)), ten up to fifty number of customers $(\mathrm{AOR}=0.26,95 \% \mathrm{CI}(0.12-0.56))$, diploma educational status $(\mathrm{AOR}=10.23,95 \%$ CI $(1.26-83.24)$ ), and having information about ethics $(\mathrm{AOR}=0.27,95 \% \mathrm{CI}$ (0.19-0.81)) were significantly associated to behavioral change of friends to unethical act (Scenario 11) (Table 5A and B).

\section{Discussion}

This study assessed ethical issues of community pharmacy professionals in an Ethiopian setting, the first of its kind in the country. It identified important baseline ethical concerns and paves the way for a wider and advanced investigation in the future. Our study revealed that two hundred and fifty-two (82.6\%) respondents received previous continuous education on ethics which is relatively higher than the result reported from a study conducted in Central Saudi Arabia (72.3\%). ${ }^{22}$ A higher report of ever received ethics education in our study is not surprising because 
Table 3 General Information on Ethical Issues Among Community Pharmacy Professionals, Amhara Region, Ethiopia, 2020 ( $\mathrm{n=305)}$

\begin{tabular}{|c|c|c|c|}
\hline Variable* & Categories* & Frequency & Percent \\
\hline \multirow[t]{2}{*}{ Ever received previous continuous education on ethics } & Yes & 252 & 82.6 \\
\hline & No & 53 & 17.4 \\
\hline \multirow[t]{2}{*}{ Ever accessed ethical information at practice site } & Yes & 274 & 89.8 \\
\hline & No & 31 & \\
\hline \multirow[t]{2}{*}{ Ever record ethical concerns in your pharmacy? } & Yes & 145 & 47.5 \\
\hline & No & 160 & 52.5 \\
\hline \multirow{5}{*}{$\begin{array}{l}\text { If you record, how often do you discuss ethical issue with } \\
\text { your customer? }\end{array}$} & Never & 4 & 2.6 \\
\hline & Rarely & 32 & 22.0 \\
\hline & Sometimes & 60 & 41.3 \\
\hline & Often & 22 & 15.7 \\
\hline & Very Often & 27 & 18.4 \\
\hline \multirow[t]{4}{*}{ The discussion of ethical issue is? } & Self-initiated & 121 & 39.7 \\
\hline & Patient-initiated conversation & 212 & 69.5 \\
\hline & One time discussion & 32 & 10.5 \\
\hline & Ongoing discussion & 42 & 13.8 \\
\hline \multirow{4}{*}{$\begin{array}{l}\text { What are the barriers that limit you from explaining } \\
\text { ethical issues with your customers? }\end{array}$} & Lack of time & 262 & 85.9 \\
\hline & Lack of reliable resources & 122 & 40 \\
\hline & Not interested in subject & 68 & 22.3 \\
\hline & Lack of ethical knowledge & 115 & 37.7 \\
\hline \multirow{4}{*}{$\begin{array}{l}\text { Which ethical reference is readily available in your } \\
\text { pharmacy (if any)? }\end{array}$} & Books & 240 & 78.7 \\
\hline & Brochures & 68 & 22.3 \\
\hline & Internet web sites & 91 & 29.8 \\
\hline & Computer databases & 34 & II.I \\
\hline \multirow{4}{*}{$\begin{array}{l}\text { Which of the following ethical resources would be helpful } \\
\text { in caring for your customers (check all that applies)? }\end{array}$} & Books & 268 & 87.9 \\
\hline & Brochures & 129 & 42.3 \\
\hline & Internet web sites & 119 & 39.0 \\
\hline & Computer databases & 95 & 31.1 \\
\hline
\end{tabular}

Notes: *Adapted from: Al-Arifi MN. Community pharmacist perception and attitude toward ethical issues at community pharmacy setting in central Saudi Arabia. Saudi Pharm J. 2014;22(4):315-325. ${ }^{22}$ With permission from Elsevier. Creative Commons CC BY-NC-ND 3.0 (https://creativecommons.org/licenses/by-nc-nd/3.0/legalcode).

pharmacy law and ethics course is given in undergraduate education of pharmacy professionals. Educational intervention appeared to positively influence graduates' professional practice. $^{31,32}$ However, significant proportion of the participants $(37.7 \%)$ in this study indicated lack of ethical knowledge as a barrier to discussing ethical issues with customers. This informs the adequacy and teaching approaches of ethics course in our country may be questionable and needs further investigation. A one-time and early exposure to ethical concepts might not also be enough. Whilst the foundation of ethical reasoning can be established in university studies, continuous professional development and practical exposure is needed to advance the skill. ${ }^{20,23}$

In the current study, two hundred and seventy-four (89.8\%) participants had accessed ethical information at the practice site. This is higher than the finding from Central Saudi Arabia (64.8\%). ${ }^{22}$ Al-Qudah et al (2019), in their study on community pharmacy ethical practice in two cities of Jordan, reported $56.6 \%$ and $24.3 \%$ of community pharmacists had ever accessed ethical information in their practice site in Amman and Irbid respectively. ${ }^{33}$ One hundred and forty-five (47.5\%) of our study participants had ever recorded ethical concerns in their working site. This is very much low in comparison with the study by Al-Arif MN (2014) where only $1.9 \%$ community pharmacists never recorded ethical issues. ${ }^{22}$ Ethical concern recording in this study was also quite inferior to a study in Jordan. ${ }^{33}$

In our study, majority of the participants had reported that "lack of time" was the major barrier $(85.9 \%)$ which hinder them to discuss ethical concerns with the customers 
Table 4 Response to Ethical Scenarios Among Community Pharmacy Professionals, Amhara Region, Ethiopia, 2020 ( $n=305$ )

\begin{tabular}{|c|c|c|c|c|c|c|c|c|c|}
\hline Scenarios & $\begin{array}{l}\text { Do Not } \\
\text { Know } \\
\text { N (\%) }\end{array}$ & $\begin{array}{l}\text { Never } \\
\text { N (\%) }\end{array}$ & $\begin{array}{l}\text { Hardly } \\
\text { Ever } \\
\text { N (\%) }\end{array}$ & $\begin{array}{l}\text { Every } \\
\text { Few } \\
\text { Months } \\
\text { N (\%) }\end{array}$ & $\begin{array}{l}\text { Once or } \\
\text { Twice } \\
\text { a Month } \\
\text { N (\%) }\end{array}$ & $\begin{array}{l}\text { Once or } \\
\text { Twice } \\
\text { a Week } \\
\text { N (\%) }\end{array}$ & $\begin{array}{l}\text { At Least } \\
\text { Once } \\
\text { a Day } \\
\text { N (\%) }\end{array}$ & $\begin{array}{l}\text { Positive } \\
\text { Respondents } \\
\text { N (\%) }\end{array}$ & $\begin{array}{l}\text { Negative } \\
\text { Respondents } \\
\text { N (\%) }\end{array}$ \\
\hline I & $4 I(13.4)$ & $65(21.3)$ & $29(9.5)$ & $85(27.9)$ & $24(7.9)$ & $29(9.5)$ & $32(10.5)$ & $170(55.7)$ & $135(44.3)$ \\
\hline 2 & $32(10.5)$ & $63(20.7)$ & $37(12.1)$ & $52(17.0)$ & $23(7.5)$ & $35(11.5)$ & $63(20.7)$ & $173(56.7)$ & $132(43.3)$ \\
\hline 3 & $40(13.1)$ & $109(35.7)$ & $44(14.4)$ & $5 I(16.7)$ & $47(15.4)$ & $3(1.0)$ & $\mathrm{II}(3.6)$ & $112(36.7)$ & $193(63.3)$ \\
\hline 4 & 7II(23.3) & $80(26.2)$ & $37(12.1)$ & $45(14.8)$ & $30(9.8)$ & $8(2.6)$ & $34(11.1)$ & $117(38.4)$ & $188(61.6)$ \\
\hline 5 & $63(20.7)$ & 7I(23.3) & $45(14.8)$ & $54(17.7)$ & $22(7.2)$ & $24(7.9)$ & $26(8.5)$ & $126(4 \mid .3)$ & $179(58.7)$ \\
\hline 6 & $6 \mathrm{I}(20.0)$ & $68(22.3)$ & $42(13.8)$ & $53(17.4)$ & $25(8.2)$ & $25(8.2)$ & $31(10.2)$ & I34(43.9) & $17 \mid(56.1)$ \\
\hline 7 & $25(8.2)$ & $40(13.1)$ & $37(12.1)$ & $65(21.3)$ & $4 I(I 3.4)$ & $45(\mid 4.8)$ & $52(17.0)$ & $203(66.6)$ & $102(33.4)$ \\
\hline 8 & $32(10.5)$ & $56(18.4)$ & $4 I(13.4)$ & $44(\mid 4.4)$ & $62(20.3)$ & $15(4.9)$ & $55(18.0)$ & $176(57.7)$ & $129(42.3)$ \\
\hline 9 & $91(29.8)$ & $78(25.6)$ & $30(9.8)$ & $4 I(13.4)$ & $24(7.9)$ & $18(5.9)$ & $23(7.5)$ & $106(34.8)$ & $199(65.2)$ \\
\hline 10 & $68(22.3)$ & $86(28.2)$ & $53(17.4)$ & $5 I(16.7)$ & $5(1.6)$ & $22(7.2)$ & $20(6.6)$ & $98(32.1)$ & $207(67.9)$ \\
\hline II & $73(23.9)$ & $74(24.3)$ & $66(21.6)$ & $25(8.2)$ & $21(6.9)$ & $22(7.2)$ & $24(7.9)$ & $92(30.2)$ & $213(69.8)$ \\
\hline 12 & $24(7.9)$ & $80(26.2)$ & $29(9.5)$ & $62(20.3)$ & $33(10.8)$ & $4 I(13.4)$ & $36(11.8)$ & $172(56.4)$ & $133(43.6)$ \\
\hline 13 & $59(19.3)$ & $100(32.8)$ & $45(\mid 4.8)$ & $39(12.8)$ & $24(7.9)$ & $9(3.0)$ & $29(9.5)$ & $101(33.1)$ & $204(66.9)$ \\
\hline 14 & $123(40.3)$ & $109(35.7)$ & $25(8.2)$ & $26(8.5)$ & $7(2.3)$ & $3(1.0)$ & $12(3.9)$ & $48(15.7)$ & $257(84.3)$ \\
\hline 15 & $103(33.8)$ & $98(32.1)$ & $26(8.5)$ & $35(11.5)$ & $22(1.7)$ & $8(2.6)$ & $13(4.3)$ & $78(25.6)$ & $227(74.4)$ \\
\hline 16 & $65(21.3)$ & $\mid 26(4 \mid .3)$ & $44(14.4)$ & $20(6.6)$ & $25(8.2)$ & $17(5.6)$ & $8(2.6)$ & $70(22.9)$ & $235(77.1)$ \\
\hline 17 & $6 \mathrm{I}(20.0)$ & I52(49.8) & $49(16.1)$ & $16(5.2)$ & $13(4.3)$ & $3(1.0)$ & II (3.6) & $43(14.1)$ & $262(85.9)$ \\
\hline 18 & $5 \mathrm{I}(16.7)$ & $8 I(26.6)$ & $45(14.8)$ & $58(19.0)$ & $23(7.5)$ & $22(7.2)$ & $25(8.2)$ & $128(42.0)$ & $177(58.0)$ \\
\hline 19 & $5 I(16.7)$ & $83(26.6)$ & $45(14.8)$ & $59(19.0)$ & $20(7.5)$ & $22(7.2)$ & $25(8.2)$ & $\mid 26(4 \mid .3)$ & $179(58.7)$ \\
\hline
\end{tabular}

followed by "lack of reliable resources" (40.0\%) and "poor ethical knowledge" (37.7\%). This finding is similar with other studies in Jordan, ${ }^{33}$ Saudi Arabia $^{22}$ and Scotland. ${ }^{34}$ However, in another study conducted in Iran poor experience with ethical issues and absence of trust were reported to be major barriers against explaining ethical issues. ${ }^{35}$ The majority of the participants (78.7\%) reported that books were the primary ethical reference materials available in their pharmacy followed by internet (29.8\%). The preferred resources for referring ethical information were comparable to a study in Saudi Arabia. ${ }^{22}$ Contrary to this, according to the study in Jordan, pharmacist mostly use internet websites to help them in resolving ethical issues concerning their patients. $^{33}$

Out of the 19 ethical scenarios, for only 5 scenarios, more than $50 \%$ of the community pharmacy professionals reported ever encountered such cases. This could be due to the ethical inattentiveness of the professionals which makes it difficult to recall ethical issues in their work. Cooper et al (2007) revealed ethical passivity presents a formidable challenge to ethical pharmacy practice. It is expressed in the form of inability to identify and recount ethical problems, failure to articulate value concepts, giving concern to legal prosecution or disciplinary action in relation to how an ethical problem should be dealt, and hesitation from acting upon one has decided. ${ }^{24}$ Irrespective of how frequent the encounter is, Scenario 7, 8, 12, 1 and 2 were the most commonly detected ethical issues by our respondents in decreasing order. On the other hand, Scenario 17, 14, 16 and 15 were least commonly detected ethical issues in increasing order. There is discrepancy in the frequency of detection for each scenarios in our study and what was reported in previous studies elsewhere. ${ }^{14,22}$ This could be attributed to difference in focus area of ethical training, code of ethics, legal framework, religious and cultural values, and financial concerns in the countries. Although recalling ever facing of the ethical scenarios does not mean community pharmacy professionals expressed their agreement with a specific decision or action, indirect implications can be inferred. Scenario 7 and 12 may indicate lack of concern to confidentiality of patient information. Patient autonomy was also found to be compromised as in the case of Scenario 8. Based on Scenario 1, financial pressure and customer satisfaction outweighed ethical values. In Ethiopia, generic substitution is legally permitted for pharmacy professionals and this may be a driving factor for Scenario 2 to be within the 


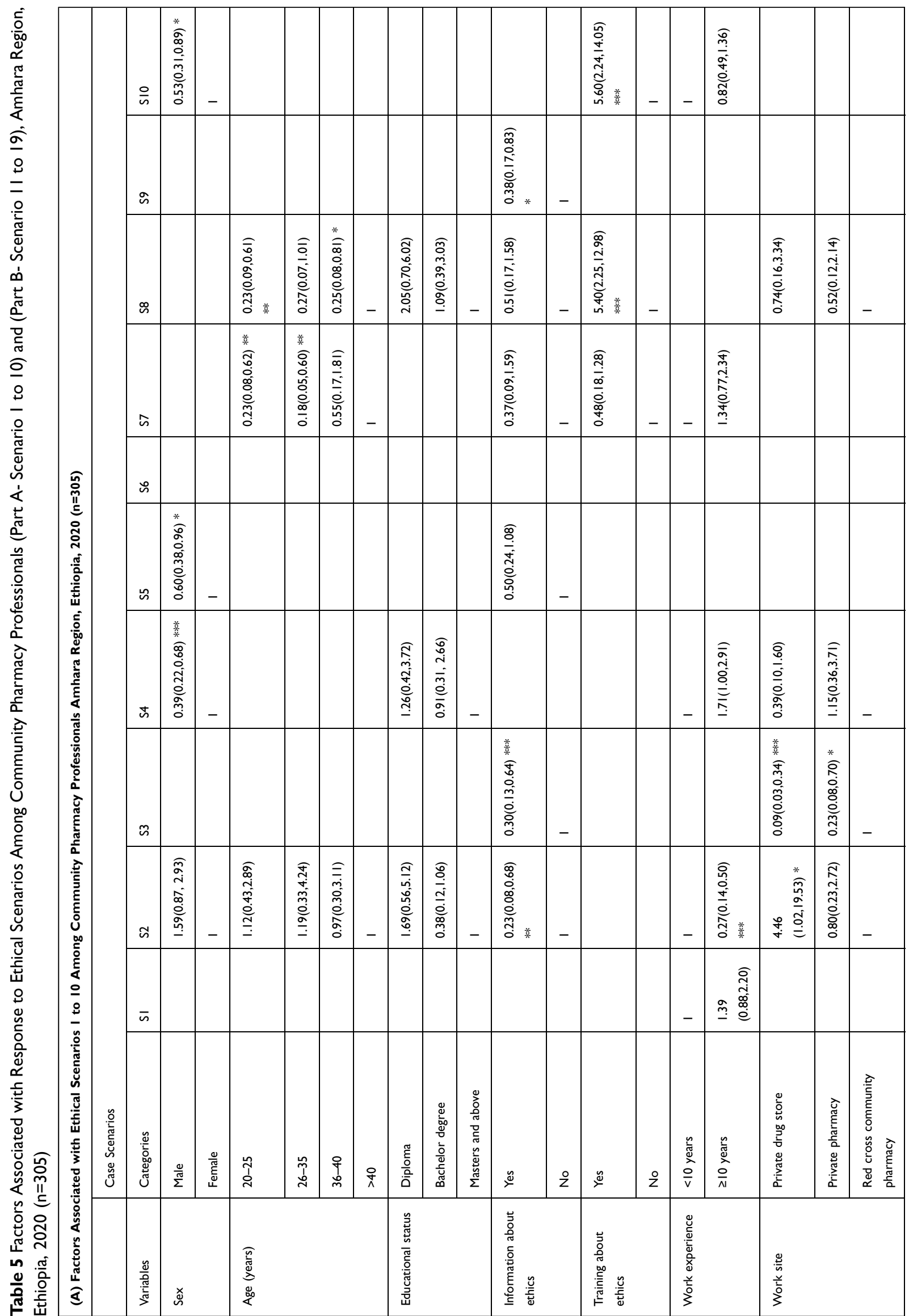




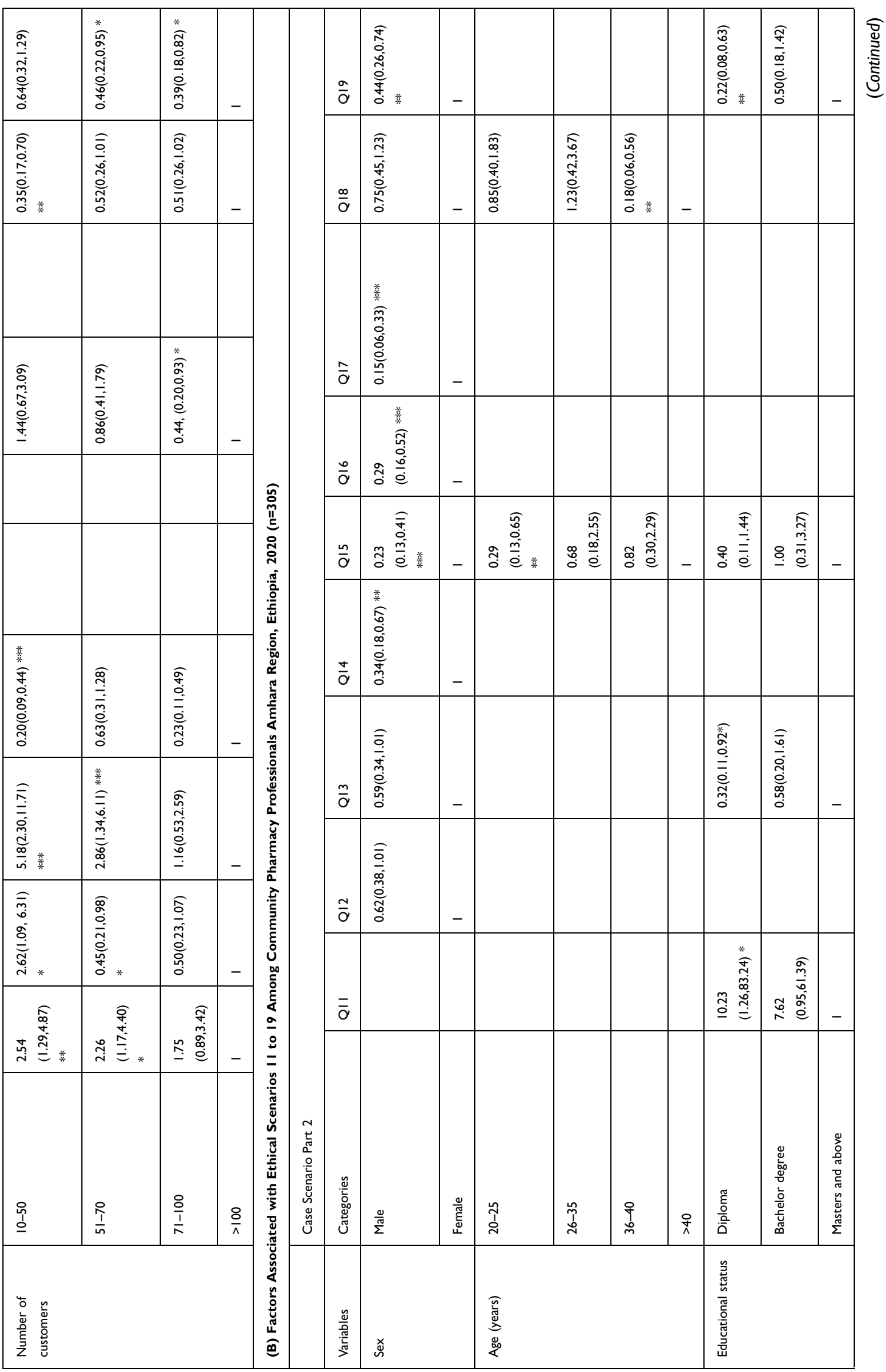




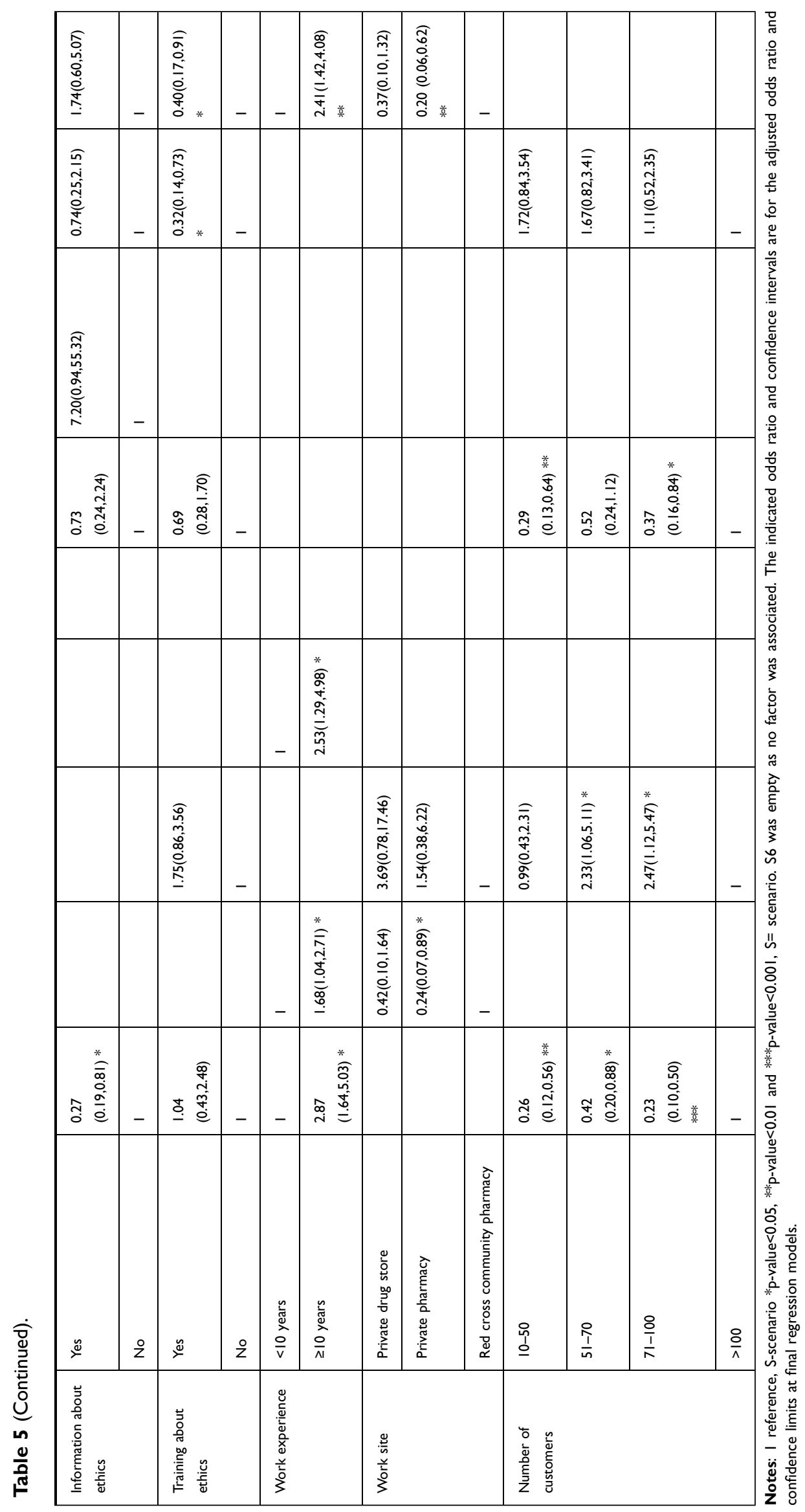


top five encountered issue and the most frequent daily detected of all 19 scenarios.

Several factors contributed to the occurrence of poor attitude and perception towards different scenarios. Sex, age, educational status, work experience, number of customers per day, working site, information about ethics and training about ethics were observed to have significant association with attitude and perceptions (scenarios) of community pharmacy professionals. In the current study, female community pharmacy professionals encountered more ethical issues regarding confidentiality (Scenario 19) as compared to male participants. This finding is the same with other study. ${ }^{36}$ Work experience was also another significant factor impacting attitude and perception of ethical issue. In the current study, experienced study subjects (more than 10 years) encountered ethical dilemma regarding confidentiality than those with lesser experience. This is against previous findings. ${ }^{36,37}$ Those who received training about ethics were less likely to encounter ethical dilemma as compared to those with no training. This is not surprising as training will help pharmacy professionals on how to handle ethical dilemma. Educational status was found inconsistently associated with different ethical questions. For example, it was inversely associated with confidentiality (Scenario 19) where as it was positively associated with Scenario 11. It was not associated with other case scenarios. Similar to these finding, several previous studies indicated variation about association of educational status with attitude and perception. ${ }^{38-40}$ In this study, number of customers who visit the particular pharmacy, prior information about ethics and working in either of the public or private pharmacy were also factors identified to have an impact on attitude and perception.

This study has its own limitations. The study is confined to selected towns in Amhara region. So, our finding cannot be generalized to community pharmacy practice in the whole region or country level. Recall bias among community pharmacy professionals is also one of the drawbacks of the study. We assessed whether and how frequent community pharmacy professionals encountered selected ethical scenarios as a reflection of attitude and perception. However, had we used a Likert scale questionnaire concerning their agreement with specific decision on ethical scenarios, the attitude and perception of the pharmacy professionals would have been clearly identified. The options provided as barriers preventing ethical discussion with customers are limited which narrowed down multitude of factors affecting ethical decision-making.
The adequacy of undergraduate ethical education and the practical application of the Ethiopian code of ethics for pharmacy professionals were not assessed. We could not get a similar study from western countries for comparison purpose.

\section{Conclusion}

Most study participants had taken continuous education and ever accessed ethical information at their practice site. Community pharmacy professionals poorly recorded ethical problems they encountered. Lack of time was the major barrier that limits them to discuss ethical concerns with their customers followed by absence of reliable resources and poor ethical knowledge. Response to scenarios implied poor attitude and perception towards ethical issues. Interventions should be devised to uphold ethical awareness of community pharmacy professionals. A largescale study is recommended to investigate the adequacy and teaching approaches of ethics course in undergraduate pharmacy education, practical application of pharmacy professionals' code of ethics, and ethical decision-making.

\section{Data Sharing Statement}

The dataset of this research is found at the primary author (Wudneh Simegn) and it can be provided up on request.

\section{Ethical Consideration}

We have obtained ethical approval and letter of cooperation from the School of Pharmacy, University of Gondar. All the study participants were included voluntarily after getting informed consent. Written consent was obtained from the participants. All respondents were informed the confidentiality of information (no identifiers), the purpose of the research and its importance. They were also told not to respond to unwanted questions, or not to participate totally.

\section{Acknowledgments}

The authors acknowledged the University of Gondar, study participants, and study facilitators.

\section{Author Contributions}

All authors made a significant contribution to the work reported, whether that is in the conception, study design, execution, acquisition of data, analysis and interpretation, or in all these areas; took part in drafting, revising or critically reviewing the article; gave final approval of the version to be published; have agreed on the journal to 
which the article has been submitted; and agree to be accountable for all aspects of the work.

\section{Funding}

This research was not funded by any agent.

\section{Disclosure}

All authors declare no conflicts of interest for this work.

\section{References}

1. Melton BL, Lai Z. Review of community pharmacy services: what is being performed, and where are the opportunities for improvement? Integr Pharm Res Pract. 2017;6:79-89. doi:10.2147/IPRP.S107612

2. Davies JE, Barber N, Taylor D. What do community pharmacists do?: results from a work sampling study in London. Int $J$ Pharm Pract. 2014;22(5):309-318. doi:10.1111/ijpp.12083

3. International Pharmaceutical Federation, World Health Organization. Joint FIP/WHO guidelines on good pharmacy practice: standards for quality of pharmacy services; 2010. Available from: https://www.fip. org/files/fip/WHO/GPP\%2520guidelines\%2520FIP\%2520publica tion_final.pdf. Accessed August 19, 2021.

4. International Pharmaceutical Federation. Good pharmacy practice in developing countries: recommendations for step-wise implementation; 1998. Available from: https://www.fip.org/files/fip/Statements/GPP\% 20recommendations.pdf. Accessed August 19, 2021.

5. World Health Organization Regional Office for Europe. The legal and regulatory framework for community pharmacies in the WHO European region; 2019. Available from: https://apps.who.int/iris/han dle/10665/326394. Accessed August 19, 2021.

6. Kruijtbosch M, Göttgens-Jansen W, Floor-Schreudering A, van Leeuwen E, Bouvy ML. Moral dilemmas of community pharmacists: a narrative study. Int J Clin Pharm. 2018;40(1):74-83. doi:10.1007/ s11096-017-0561-0

7. Delpasand K, Afshar L, Tavakkoli SN. The ethical principles in pharmacist-patient relationship. J Clin Diagn Res. 2019;13(3): FE01-FE03.

8. Chaar B, Brien J, Krass I. Professional ethics in pharmacy: the Australian experience. Int $J$ Pharm Pract. 2005;13(3):195-204. doi:10.1211/ijpp.13.3.0005

9. Sharif PS, Javadi M, Asghari F. Pharmacy ethics: evaluation pharmacists' ethical attitude. J Med Ethics Hist Med. 2011;4:5.

10. Morris K, Arzoomanian A. Insights from regulatory data on development needs of community pharmacy professionals. Pharmacy. 2020;8(3):111. doi:10.3390/pharmacy8030111

11. Hepler CD, Strand LM. Opportunities and responsibilities in pharmaceutical care. Am J Hosp Pharm. 1990;47(3):533-543.

12. Mossialos E, Courtin E, Naci H, et al. From "retailers" to health care providers: transforming the role of community pharmacists in chronic disease management. Health Policy (New York). 2015;119 (5):628-639. doi:10.1016/j.healthpol.2015.02.007

13. Hutchings HA, Rapport FL, Wright S, Doel MA, Wainwright $P$. Obtaining consensus regarding patient-centred professionalism in community pharmacy: nominal group work activity with professionals, stakeholders and members of the public. Int J Pharm Pract. 2010;18(3):149-158. doi:10.1211/ijpp.18.03.0004

14. Rodríguez JV, Juričić Ž. Perceptions and attitudes of community pharmacists toward professional ethics and ethical dilemmas in the workplace. Res Social Adm Pharm. 2018;14(5):441-450. doi:10.1016/j.sapharm.2017.05.010
15. Rajiah K, Venkataraman R, Samuel N, et al. Community pharmacists' perceptions on ethical dilemmas, pharmacy values and decision-making. Indian J Pharm Pract. 2018;11(4):169. doi:10.5530/ ijopp.11.4.36

16. Hedenrud T, Håkonsen H. Purchase habits, use of paracetamol, and information sources on a reregulated Swedish pharmacy market: a Population-Based Study. Health Policy (New York). 2017;121 (1):35-41. doi:10.1016/j.healthpol.2016.11.009

17. Fumagalli LP, Radaelli G, Lettieri E, Masella C. Patient empowerment and its neighbours: clarifying the boundaries and their mutual relationships. Health Policy (New York). 2015;119(3):384-394. doi:10.1016/j.healthpol.2014.10.017

18. Kruijtbosch M, Göttgens-Jansen W, Floor-Schreudering A, van Leeuwen E, Bouvy ML. Moral dilemmas reflect professional core values of pharmacists in community pharmacy. Int $J$ Pharm Pract. 2019;27(2):140-148. doi:10.1111/ijpp. 12490

19. Cooper R, Bissell P, Wingfield J. Dilemmas in dispensing, problems in practice? Ethical issues and law in UK community pharmacy. Clin Ethics. 2007;2(2):103-108. doi:10.1258/147775007781029564

20. Sim TF, Sunderland B, Hattingh HL. Exploring influences on pharmacists' and students' ethical reasoning in a changing practice landscape in Australia. Int $J$ Clin Pharm. 2019;41(1):280-288. doi:10.1007/s11096-018-0774-x

21. Fino LB, Basheti IA, Saini B, Moles R, Chaar BB. Exploring pharmacy ethics in developing countries: a scoping review. Int $J$ Clin Pharm. 2020;42(2):418-435. doi:10.1007/s11096-020-01021-4

22. Al-Arifi MN. Community pharmacist perception and attitude toward ethical issues at community pharmacy setting in central Saudi Arabia. Saudi Pharm J. 2014;22(4):315-325. doi:10.1016/j.jsps.2013.08.003

23. San Saw P, Chuah LH, Lee SWH. A practical approach toward teaching ethics to community pharmacists. Int $J$ Clin Pharm. 2018;40(5):1131-1136. doi:10.1007/s11096-018-0707-8

24. Cooper RJ, Bissell P, Wingfield J. Ethical decision-making, passivity and pharmacy. $J$ Med Ethics. 2008;34(6):441-445. doi:10.1136/ jme.2007.022624

25. Cooper R, Bissell P, Wingfield J. Islands' and doctor's tool': the ethical significance of isolation and subordination in UK community pharmacy. Health: 2009;13(3):297-316. doi:10.1177/136345930 8101805

26. Altilio JV. The pharmacist's obligations to patients: dependent or independent of the physician's obligations? J Law Med Ethics. 2009;37(2):358-368. doi:10.1111/j.1748-720X.2009.00379.x

27. Cipolle RJ, Strand LM, Morley PC. Pharmaceutical Care Practice: The Patient-Centered Approach to Medication Management. McGraw Hill Professional; 2012.

28. Cooper R, Bissell P, Wingfield J. A new prescription for empirical ethics research in pharmacy: a critical review of the literature. $J$ Med Ethics. 2007;33(2):82-86. doi:10.1136/jme.2005.015297

29. Ayele AA, Mekuria AB, Tegegn HG, Gebresillassie BM, Mekonnen AB, Erku DA. Management of minor ailments in a community pharmacy setting: findings from simulated visits and qualitative study in Gondar town, Ethiopia. PLoS One. 2018;13(1): e0190583. doi:10.1371/journal.pone.0190583

30. Erku DA, Aberra SY. Non-prescribed sale of antibiotics for acute childhood diarrhea and upper respiratory tract infection in community pharmacies: a 2 Phase Mixed-Methods Study. Antimicrob Resist Infect Control. 2018;7(1):92. doi:10.1186/s13756-018-0389-y

31. Kheir N, Awaisu A, Ibrahim S, Al-Dulaimi SM, Gad H. Perspectives of pharmacy graduates toward an undergraduate ethics course and its potential impact on their professional practice. Adv Med Educ Pract. 2019;10:1047-1056. doi:10.2147/AMEP.S224093

32. Okoro RN. Investigation of final-year pharmacy students' views on professionalism and ethics in pharmacy practice: an Interventional Study. Int $J$ Pharm Pract. 2020;28(2):130-133. doi:10.1111/ ijpp. 12542 
33. Al-Qudah RA, Tuza O, Tawfiek H, Chaar B, Basheti IA. Community pharmacy ethical practice in Jordan: assessing attitude, needs and barriers. Pharm Pract. 2019;17(1):1386.

34. Rogers WA. Ethical issues in public health: a Qualitative Study of public health practice in Scotland. J Epidemiol Community Health. 2004;58(6):446-450. doi:10.1136/jech.2003.013417

35. Delpasand K, Kiani M, Afshar L, Tavakkoli SN. Extracting the ethical challenges of pharmacy profession in Iran, a Qualitative Study. J Res Med Dent Sci. 2018;6(1):52-58.

36. Rajiah K, Venaktaraman R. The effect of demographic and social factors on the decision-making of community pharmacists in ethical dilemmas. J Res Pharm Pract. 2019;8(3):174. doi:10.4103/jrpp. JRPP_19_15
37. Rajiah K, Venkataraman R. Social determinants associated with ethical decision-making among community pharmacists. Ethics Med Public Health. 2020;14:100512. doi:10.1016/j.jemep.2020.100512

38. Pauly BM, Varcoe C, Storch J, editors. Framing the Issues: Moral Distress in Health Care. Hec Forum, Springer; 2012.

39. Fritzsche D, Oz E. Personal values' influence on the ethical dimension of decision making. $J$ Bus Ethics. 2007;75(4):335-343. doi:10.1007/s10551-006-9256-5

40. Doyle E, O'Flaherty J. The impact of education level and type on moral reasoning. Irish Educ Stud. 2013;32(3):377-393. doi:10.1080/ 03323315.2013 .823273

\section{Publish your work in this journal}

Risk Management and Healthcare Policy is an international, peerreviewed, open access journal focusing on all aspects of public health, policy, and preventative measures to promote good health and improve morbidity and mortality in the population. The journal welcomes submitted papers covering original research, basic science, clinical \& epidemiological studies, reviews and evaluations, guidelines, expert opinion and commentary, case reports and extended reports. The manuscript management system is completely online and includes a very quick and fair peer-review system, which is all easy to use. Visit http://www.dovepress.com/testimonials.php to read real quotes from published authors.

Submit your manuscript here: https://www.dovepress.com/risk-management-and-healthcare-policy-journal 